\title{
ОСНОВАНИЯ НАСЛЕДОВАНИЯ В РОССИЙСКОМ НАСЛЕДСТВЕННОМ ПРАВЕ: ТРАДИЦИИ И НОВАЦИИ
}

Актуальность темы исследования предопределена огромным практическим потенциалом вопросов наследования имущества. Ведь не вызывает сомнения тот факт, что наследственное право в определенной степени затрагивает интересы каждого гражданина действующее сегодня наследственное законодательство существенным образом отличается от советского аналога. Часть третья ГК РФ, которая является основным источником современного наследственного права демонстрирует качественно новый уровень правового регулирования отношений наследования. Вместе с тем российское наследственное законодательство не лишено недостатков, пробелов и противоречий, что относится и к теме нашего исследования. Сказанное побудило авторов обратиться к анализу вопросов об основаниях наследования. Новизна данной работы заключается в попытке введения в научный оборот новых правовых конструкций, предусмотренных Федеральным законом от 19.07.2018 N 217-Ф3 «О внесении изменений в статью 256 части первой и часть третью Гражданского кодекса Российской Федерации». Речь идет о наследственном договоре как новом основании наследования. Проведенное исследование опирается на специальные юридические методы: "исторический и сравнительно-правовой.. Использование исторического метода исследования позволило авторам выявить преемственность правового регулирования оснований наследования, а также оценить новую правовую конструкцию «наследственный договор» с точки зрения традиций правового регулирования отношений наследования. Основания наследования исследованы авторами с применением сравнительно-правового подхода, позволяющего сравнить российский и зарубежный опыт правового регулирования в рассматриваемой сфере с целью выявления общих принципов и различий. Сформулированы предложения по совершенствованию правового регулирования отношений наследования на основании наследственного договора."

Ключевые слова: наследственное право, основания наследования, наследование по завещанию, наследование по закону, наследственный договор.

M. Melnikova, I. Komarevtseva

\section{THE GROUNDS OF INHERITANCE IN RUSSIAN INHERITANCE LAW}

The relevance of the research topic is predetermined by enormous practical potential of property inheritance issues. After all, there is no doubt that the law of succession to a certain extent affects the interests of every citizen. The current hereditary legislation is significantly different from the Soviet counterpart. Part three of the Civil Code of the Russian Federation, which is the main source of modern inheritance law, demonstrates a qualitatively new level of legal regulation of inheritance relations. At the same time, the Russian hereditary legislation is not without flaws, gaps and contradictions, which applies to the topic of our research. This prompted the authors to turn to the analysis of issues related to the grounds for inheritance. The novelty of this work lies in the attempt to introduce into scientific circulation new legal constructions stipulated by the Federal Law of 19.07.2018 N217-FZ "On Amendments to Article 256 of Part One and Part Three of the Civil Code of the Russian Federation". This is a hereditary contract as a new

В ходе развития наследственного права получили свое оформление два основания наследования: завещание и закон. При изучении проблемы оснований наследования закономерно возникает вопрос о времени возникновения существующих сегодня оснований наследования. basis for inheritance. The study is based on special legal methods: historical and comparative legal. The use of the historical method of research allowed the authors to identify the continuity of the legal regulation of the grounds for inheritance, as well as to evaluate the new legal construction of the "hereditary contract" from the point of view of the traditions of the legal regulation of inheritance relations. The grounds for inheritance are investigated by the authors using a comparative legal approach, which makes it possible to compare Russian and foreign experience in legal regulation in this area in order to identify common principles and differences. The article provides proposals to improve the legal regulation of relations of inheritance based on a hereditary contract.

Key words: inheritance law, grounds of inheritance, testamentary succession, intestate succession, hereditary contract.

Многие авторы обращались к анализу проблемы «первенства появления» того или иного основания наследования. Анализ точек зрения по обозначенному вопросу позволяет сформулировать вывод о том, что наследование по закону - это первый по времени, «естественный» 
вид наследственного правопреемства. Сущность наследования по закону метко выражена в одном средневековом изречении, относящемся к характеристике древне-германского наследственного права: «Solus Deus heredem facere potest non homo» - только Бог может определить личность наследника, но не человек. Яков Канторович в своей работе «Основные идеи гражданского права» по этому поводу писал, что «исторически наследование по закону предшествовало наследованию по завещанию. Первоначально, по древнему праву, которое было проникнуто началами общинного и родового быта, существовало только наследование по закону; завещательный порядок наследования этому праву неизвестен» [7, с. 289]. Аналогичным образом рассуждал И. А. Покровский, по мнению которого, древнейшее право отмечено существованием единственного вида наследования - наследования по закону [17, с. 298]. Итак, институт наследования по закону сопровождал человеческое общество на протяжении долгого времени, на различных этапах его развития.

В соответствии с действующим до 01 июня 2019 года законодательством РФ наследование осуществляется по двум основаниям: по завещанию и по закону (ст. 1111 ГК РФ). На первый взгляд, перед нами четкая и лаконичная формулировка, исключающая двусмысленное толкование. Однако, в цивилистической науке ведутся оживленные дискуссии по вопросу о существующей в российском правопорядке системе оснований наследования. Так, например, советские авторы О. С. Иоффе и В. К. Дронников помимо указанных в законе двух оснований выделяли еще и третье: О. С. Иоффе указывал на наследование по основанию выморочности наследственного имущества, а В. К. Дронников определял основанием наследования «право на обязательную долю» $[21$, c. 23]. Несмотря на то, что авторы сформулировали свои выводы применительно к советскому наследственному законодательству, их высказывания не потеряли своей актуальности и в настоящее время, так как законодатель сохранил преемственность правовой регламентации системы оснований наследования. В качестве комментария к отмеченной позиции считаем возможным отметить, что упомянутые «иные»основания наследования - выморочность имущества и наследование обязательной доли - следует рассматривать как частный случай наследования по закону, о чем, в частности свидетельствует местоположение соответствующих норм (они расположены в Главе 63 ГК РФ «Наследование по закону».

Особо следует остановиться на положениях ст. 1152 ГК РФ, которые осложняют понимание вопроса о системе оснований наследования. В п.2 ст. 1152 ГК РФ говорится о том, что наследник может быть призван к наследованию по нескольким основаниям: по завещанию и по закону или в порядке наследственной трансмиссии и в результате открытия наследства и тому подобное. Данная формулировка позволила некоторым автором сформулировать вывод о том, что рос- сийское гражданское законодательство предусматривает более двух оснований наследования. Так, например, Э. Г. Пилипсон с опорой на положения ст. 1152 ГК РФ говорит о множественности оснований наследования [16]. Однако, большинство авторов критикуют содержащееся в ст. 1152 ГК РФ законодательное решение. Так, например М. С. Абраменков упрекает законодателя в терминологической неточности и предлагает в данном случае вести речь не об основаниях наследования, а об основаниях принятия наследства [1]. Со своей стороны, отметим, что перечень оснований наследования исчерпывающим образом обозначен в императивной норме ст. 1111 ГК РФ. В этой связи предложенное Э.Г Пилипсоном толкование п. 2 ст. 1152 ГК РФ противоречит содержанию и смыслу ст. 1111 ГК РФ. Сложившуюся ситуацию мы можем объяснить несовершенством законодательной техники.

Некоторые ученые критикуют употребляемый законодателем термин «основание наследования». Так, например, В. А. Белов утверждает, что и закон, и завещание следует рассматривать в качестве источников гражданского права. В этой связи автор определяет завещание и закон как акты, в которых содержатся формально закрепленные обязательные правила поведения, исполнение которых обеспечивается государственным принуждением. Другое дело, что завещание будет относиться к числу так называемых ненормативных источников, то есть источников предписаний, касающихся отдельного конкретного случая (не имеющих всеобщего значения). И закон, и завещание определяют круг лиц, подлежащих призванию к наследованию; разница в том, что закон это делает для всех случаев определенного рода и вида а завещание - для единственного случая открытия конкретного наследства. Закон есть необходимое условие существования наследственного права в целом как подотрасли гражданского права. Завещание - это столь же необходимое условие возникновения данного конкретного наследственного правоотношения [3, с. 977]

Резюмируя все сказанное В. А. Беловым, отметим, что по сути, он рассматривает завещание и закон как два различных способа определения круга лиц (наследников), подлежащих призванию к наследованию.

В. И. Серебровский, рассматривая основания призвания к наследованию на основе норм советского права, пришел к следующему актуальному и для действующего законодательства выводу: при наследовании по закону, непосредственно сам закон основанием наследования не является, ведь наследование не возникает из него. Фактически наследование возникает из совокупности предусмотренных законом юридических фактов, то есть из фактического состава. Так, при наследовании по закону требуется наличие следующих юридических фактов: смерть наследодателя (биологическая или же юридическая), состояние в браке с наследодателем, наличие родства с наследодателем, и т.п. Сказанное в полной мере относится и к наследованию по завещанию [19, c. $48-49]$ 
Таким образом, как для наследования по завещанию, так и для наследования по закону необходим целый перечень предусмотренных законом юридических фактов. Вместе с тем, по справедливому утверждению Ю. К. Толстого, отсутствие хотя бы одного из них исключает призвание наследника к наследованию по крайней мере по тому основанию, по которому он был бы призван к наследованию, если бы весь этот перечень был налицо $[18$, с. 8].

В ходе анализа нормы ч. 1 ст. 1111 ГК РФ обращает на себя внимание порядок, в котором перечислены виды наследственного правопреемства. Так, на первое место законодатель поместил наследование по завещанию, а на второе - наследование по закону. Следует отметить, что наследование по завещанию поставлено на первое место не только в ст. 1111 ГК РФ, но и в целом в разделе V ГК РФ: наследованию по завещанию посвящена глава 62, за которой следует глава 64 «Наследование по закону».

Таким образом, данная норма еще раз подтверждает, что наследование по завещанию является ведущим основанием [20], а наследование по закону носит подчиненный, субсидиарный характер [12, с. 24].

Также Конституционный суд РФ подчеркнул приоритетный характер выраженной в завещании воли частного лица - наследодателя. Что касается наследования по закону, то в соответствии со ст. 1111 ГК РФ, оно имеет место, когда и поскольку оно не изменено завещанием [15].

В ходе рассмотрения положений об основаниях наследования, закономерно возникает вопрос о соотношении наследования по завещанию и наследования по закону. Ученые неоднократно обращались к рассмотрению данной проблемы. По этому поводу ещё дореволюционный ученый-цивилист Г. Ф. Шершеневич писал: «С точки зрения догматической, в настоящее время наследование по закону является восполнением наследования по завещанию, вступая в силу тогда и настолько, когда и насколько не успела выразиться воля наследодателя о судьбе оставленного им имущества. Догматическое соотношение между обоими видами не изменится от признания наследования по завещанию только допускаемой законом заменой законного наследования, вариацией на законную тему» [22, с. 618]. Как видим, ученый не стремится противопоставлять основания наследования, он подчеркивает, что указанные основания одинаково значимы. Однако, подобные положения оспариваются некоторыми авторами. В развитие отмеченной позиции уместно привести точку зрения авторов, которые полагают, что выделение оснований наследования имеет значение только в плоскости призвания данного лица в качестве наследника. Другой дореволюционный правовед, основоположник российской цивилистики Д. И. Мейер также отмечал условный характер "самодостаточности" оснований наследования, указывая, что «....само наследование по завещанию ... собственно есть законное». Также автор подчеркивал, что смысл выделения осно- ваний наследования заключается в определении круга наследников, в чью пользу открывается наследство [11, с. 411].

Современные ученые, в частности, М. П. Мельникова, также отмечают, что «...и наследование по завещанию и наследование по закону основаны на законе и осуществляются в строгом соответствии с правилами, предусмотренными законом. Поэтому не следует противопоставлять друг другу основания наследования. Наследование по закону и наследование по завещанию являются способами осуществления наследственного преемства» $[12$, с. 23].

Подводя итог сказанному, мы с уверенностью можем утверждать, что современный законодатель в части третьей ГК РФ следуя уже сложившейся правовой традиции, сохранил систему оснований наследования в виде наследования по завещанию и наследования по закону. Однако, приоритеты регулирования отношений наследования принципиально изменились. Главную роль теперь играет наследование по завещанию, а наследование по закону носит подчиненный, субсидиарный характер. Кроме того, завещание и закон, будучи основаниями наследования, по сути, определяют порядок развития наследственных правоотношений (по воле завещателя или по воле законодателя).

На сегодняшний день в российском наследственном законодательстве наметилась тенденция расширения перечня оснований наследования.

Так, с 01 июня 2019 года самостоятельным способом распоряжения имуществом на случай смерти наряду с завещанием стал наследственный договор, имплементированный в российское наследственное право из законодательной практики зарубежных стран. Наследственный договор известен правопорядкам таких стран, как Германия, Испания, Франция, Украина, Латвия, и др. Так, например, он широко применяется в Каталонии, и представляет собой, наряду с законным, «добровольное наследование» $[10$, с. 113]. Гражданский кодекс Латвийской Республики (далее - ГК Латвии) предоставляет наследодателю возможность выразить свою волю не только в завещании, но и в соглашении о наследовании (ст.389 ГК Латвии). Сложный порядок договорного наследования предусматривает Французский гражданский кодекс (далее - ФГК). При этом, такое распоряжение наследственным имуществом, как считает Ю. Б. Гонгало, возможно лишь в качестве исключения, “действительно при соблюдении строго определённых условий $[4$, с. 86-87], и напрямую зависит от наличия брачного контракта или факта состояния супругов в браке.

Для российского правопорядка наследственный договор является абсолютно новым основанием наследования. На всех этапах развития отечественного наследственного права, традиционными основаниями наследования выступали закон и завещания, наследственный договор не был нормативно регламентирован. Однако, если обратиться к древнему периоду развития российского праву, когда основным источником 
права выступала Русская Правда, можно с определенной долей условности говорить об использовании договорной конструкции, в рамках наследственных отношений. Речь идет о так называемом «ряде», который некоторыми авторами характеризовался как договор между всеми членами семьи, с главным участием отца, об общем семейном имуществе [14, с. 52]. Следует признать, что новые правила ГК РФ о наследственном договоре, требуют пристального внимания со стороны всех заинтересованных лиц и дополнительного изучения на предмет соответствия российской традиции наследственно-правового регулирования [13].

Возможность включения которого в нормы ГК РФ вызвала в юридической литературе научные дискуссии. Сложились противоположные позиции. Так, М. С. Абраменкова считает, что «наследственный договор противоречит принципам и сущности свободы завещания и сущности приобретения наследства и поэтому не может быть признан в силу ст. 8 ГК самостоятельным основанием наследования наряду с основаниями наследования по завещанию и по закону» [2]. С. А. Степанов, комментируя ст. 1111 ГКРФ пишет, что русское гражданское право во все времена отрицало возможность существования наследственного договора по мотиву безнравственности (подчеркнуто нами) таковых, прежде всего в связи с тем, что такого рода договоры фактически устраняют возможность свободного волеизъявления на случай смерти» [8, с. 8]

Активным сторонником позиции законодателя в его стремлении совершенствовать право, является В. В. Долинская, которая изучая тенденции развития и современные проблемы наследственного права России в контексте вступления в силу Федерального закона № 259-Ф3 «О внесении изменений в части первую, вторую и третью Гражданского кодекса Российской Федерации» подчеркивает, что «сомнительное» по своему содержанию правило п.1 ст.1118 ГК РФ стало одним из контраргументов в пользу и совместного завещания и наследственного договора [6]. А сточки зрения И. В. Матвеева институт наследственного договора «существенно развивает устои наследственного права" и имеет все возможности для того, «чтобы пополнить исторически сложившийся перечень оснований для призвания к наследованию» [9]. Ю. Б. Гонгало считает, что использование в отечественном наследственном законодательстве правил о наследственном договоре между супругами, аналогично правилам ФГК, возможно и соответствует «принципу диспозитивности, свойственному гражданскому праву в целом и соответственно наследственному праву как его части» [4, с. 97].

Позиция современного российского законодателя выражена в появлении новой ст. 1140.1. ГК РФ (введена Ф3 от 19.07.2018 N217-Ф3), в соответствии с которой наследодатель вправе заключить с любым из лиц, которые могут призываться к наследованию (статья 1116), договор, условия которого определяют круг наследников и порядок перехода прав на имущество наследодателя после его смерти к пережившим наследодателя сторонам договора или к пережившим третьим лицам, которые могут призываться к наследованию (наследственный договор). Сторонами наследственного договора являются наследодатель, к которому применяются правила ГК РФ о завещателе (п. 6 ст. 1118 ГК РФ) и граждане, юридические лица, а так же публично-правовые образования, с учетом требований ст. 1116 ГК РФ. Отдельно выделен наследственный договор с участием супругов. Особенностью такого супружеского наследственного договора является не только его содержание, но и порядок его прекращения. Так, в силу абз. 2 п. 5 ст. 1140.1. ГК РФ, расторжение брака до смерти одного из супругов влечет его прекращение. Аналогичные правовые последствия предусмотрены и в случае признание брака недействительным. Решен вопрос о возможной конкуренции совместного завещания супругов и наследственного договора супругов в пользу последнего, то есть наследственный договор отменяет действие составленного ранее совместного завещания супругов. Таким образом, супругам предоставлено право выбора способа совместного наследственного распоряжения общим имуществом.

Следует отметить, что нормативно не решены вопросы о том, отменяет ли наследованный договор ранее составленное завещание, вправе ли наследодатель составить завещание после заключения наследственного договора? Буквальное толкование п. 12 ст. 1140.1 ГК РФ позволяет утверждать, что после составления наследственного договора, наследодатель вправе совершать любые сделки в отношении принадлежащего ему имущества, в том числе - составлять завещание. Однако, как будут сосуществовать и исполняться наследственный договор и завещание не ясно

Наследственный договор после составления должен быть подписан его сторонами и нотариально удостоверен. Абсолютной законодательной новеллой является требование о проведении нотариусом видеофиксации процедуры заключения договора, что является еще одной гарантией прав наследников (абз. 2 п. 7 ст. 1140.1 ГК РФ).

Наследодатель вправе заключить несколько наследственных договоров с одним или несколькими лицами.

Содержание наследственного договора составляют условия о круге наследников и порядке перехода прав на имущество наследодателя после его смерти к пережившим его сторонам договора или к пережившим третьим лицам, которые могут призываться к наследованию. Считаем, что требует своей доработки вопрос о том, можно ли в договор включить условие об отстранении наследников от наследства. Специальное правило есть в ГК Латвии, Ч. 3 ст. 639 которого, императивно предусматривает, что в договоре о наследстве отстранение от наследства не допускается [5, с. 225]. Представляется, что аналогичная норма должна быть включена в ст. 1140.1 ГК РФ.

Стороны могут предусмотреть в договоре условие о душеприказчике, а так же, условие о 
возложении на участвующих в наследственном договоре лиц, которые могут призываться к наследованию, обязанность совершить какие-либо не противоречащие закону действия имущественного или неимущественного характера, в том числе исполнить завещательные отказы или завещательные возложения. Обращает на себя внимание тот факт, что законодатель предусмотрел возможность включение в наследственный договор и таких условий, относительно которых, при заключении договора было неизвестно наступят они или не наступят, в том числе от обстоятельств, полностью зависящих от воли одной из сторон (ч. 2 п. 1. ст. 1140.1 ГКРФ). Таким образом, мы обнаруживаем определённую непоследовательность законодателя в силу того, что вопрос о возможности составления “условных» завещаний до сих пор нормативно не решен, что приводит к противоречивости нотариальной практики, и требует в свою очередь от правоприменителя формирования единообразной позиции по этому достаточно сложному вопросу.

Если завещатель вправе изменить завещание в любое время самостоятельно, то изменить условия наследственного договора в одностороннем порядке нельзя. Изменение и расторжение договора возможно только при жизни сторон договора и на основании их соглашения. Наряду с добровольным предусматривается и судебный порядок, но только в связи с изменениями обстоятельств, которые имеют для сторон существенный характер. Наследодатель вправе в одностороннем порядке отказаться от наследственного договора. Для этого он должен уведомить все стороны договора и нотариально удостоверить уведомление об отказе. При этом, на наследодателя возложена обязанность по возмещению другим сторонам договора убытков, которые возникли у них в связи с исполнением наследственного договора к моменту получения копии уведомления об отказе наследодателя от договора. Стороны же договора вправе осуществить односторонний отказ от наследственного договора в порядке, предусмотренном законом или наследственным договором. Наследственный договор может быть оспорен как при жизни наследодателя, так и после открытия наследства.

В итоге проведенного исследования новелл наследственного законодательства, которые касаются системы оснований наследования, хотелось бы отметить, что введение в российский правопорядок конструкции наследственного договора является прогрессивным шагом, приближающим нас к европейской правовой традиции, однако, данный правовой институт требует своей доработки с учетом уже сложившихся в отечественном наследственном праве правовых принципов и правил.

\section{Литература}

1. Абраменков М. С. Правовой механизм принятия наследства // Нотариус. 2012. №3. С. 28-34.

2. Абраменков М. С. Общая характеристика завещания как основания наследования //Нотариус. 2010. №6. C.5-11.

3. Белов В. А. Гражданское право. Т. ІІІ. Особенная часть. Абсолютные гражданско-правовые формы: учебник. М. Издательство Юрайт, 2012. 1189 с.

4. Гонгало Ю. Б. Распоряжения наследственного характера во Французском праве /Актуальные вопросы наследственного права / под ред. П. В. Крашенинникова. М.: Статут, 2016. 112 с.

5. Гражданский кодекс Латвийской Республики / Научное редактирование и предисловие Н. Э. Лившиц. СПб.: Издательство «Юридический центр пресс», 2001. 801 с.

6. Долинская В. В. О тенденциях развития и проблемах наследственного права России // Законы России: опыт, анализ, практика. 2018. №10. С.3-13.

7. Канторович Я. Основные идеи гражданского права. М.: [б.и.], 2015. 309 с.

8. Комментарий к Гражданскому кодексу Российской Федерации(учебно-практический) к ч.3/ под ред. С. А. Степанова. М.: Проспект; Екатеринбург: Институт частного права, 2015. 152 с.

9. Матвеев И. . Наследственный договор: зарубежный опыт и перспективы появления в гражданском праве Российской Федерации URL: http://отрасли-права.рф/article/9392 (Дата обращения: 21.05.2019).

10. Медведев С. Н. Введение в гражданское право Испании.- Ставрополь: СКФУ, 2017. 139 с

11. Мейер Д. И. Русское гражданское право. Часть 2. М.: [б.и.], 1997. 455 с.

12. Мельникова М. П. Наследование по закону в России от Свода законов до Гражданского кодекса РСФСР 1964 года (историко-теоретический аспект): дисс. ... канд. юрид. наук. Ставрополь: СГУ, 2001. 222 с.

13. Мельникова М. П., Комаревцева И. А. Российское наследственное законодательство: анализ последних изменений и перспективы развития // Правовая политика и правовая жизнь. 2017. №1. С.109-117.

14. Митькевич А. О форме завещаний. Историко-юридический очерк. Тифлис, б/д. б/п.

15. Обзор дел, рассмотренных Конституционным Судом Российской Федерации // Сравнительное конституционное обозрение. 2014. №1. С.149-157.

16. Пилипсон Э.Г. Институты договорного наследования: правовые проблемы имплементации на территории российской федерации // // СПС «КонсультантПлюс».

17. Покровский И. А. Основные проблемы гражданского права. М.: Статут, 1998. 353 с

18. Сергеев А. П., Толстой Ю. К., Елисеев И. В. Комментарий к гражданскому кодексу Российской Федерации (постатейный). М.: Проспект, 2006. 304 с

19. Серебровский В. И. Избранные труды по наследственному и страховому праву. М.: Статут, 1997. 567 с.

20. Тарасова И. Н. Понятие и значение формы завещания в российском гражданском праве // Наследственное право. 2014. №3. С. 35-38.

21. Черемных Г. Г. Наследственное право России: учебник. М.: Эксмо, 2009. 510 с.

22. Шершеневич Г. Ф. Курс гражданского права. Тула: Автограф, 2001.720 с. 


\section{References}

1. Abramenkov M. S. Pravovoi mekhanizm prinyatiya nasledstva (Legal mechanism for inheritance) // Notarius. 2012. №3. P.28-34. (In Russian).

2. Abramenkov M.S. Obshchaya kharakteristika zaveshchaniya kak osnovaniya nasledovaniya (General characteristics of the will as the ground of inheritance) //Notarius. 2010. No.6. P.5-11. (In Russian)

3. Belov V. A. Grazhdanskoe pravo. Vol. III. Osobennaya chast'. Absolyutnye grazhdansko-pravovye formy: uchebnik (Civil law. V. III. The special part. Absolute civil law forms: a textbook.). Moscow: Izdatel'stvo Yurait, 2012. 1189 p. (In Russian).

4. Gongalo Yu. B. Rasporyazheniya nasledstvennogo kharaktera vo Frantsuzskom prave / Aktual'nye voprosy nasledstvennogo prava / ed by P. V. Krasheninnikova. (Orders of hereditary nature in French law / Actual issues of inheritance law). Moscow: Statut, 2016.112 p. (In Russian).

5. Grazhdanskii kodeks Latviiskoi Respubliki (Civil Code of the Republic of Latvia). St.Petersburg: Izdatel'stvo « Yuridicheskii tsentr press»), 2001. 801 p. (In Russian).

6. Dolinskaya V. V. O tendentsiyakh razvitiya i problemakh nasledstvennogo prava Rossii (On development trends and problems of inheritance law of Russia) // Zakony Rossii: opyt, analiz, praktika. 2018. No.10. P. 3-13. (In Russian).

7. Kantorovich Ya. Osnovnye idei grazhdanskogo prava. (Basic ideas of civil law). Moscow, 2015. 309 p. (In Russian)

8. Kommentarii k Grazhdanskomu kodeksu Rossiiskoi Federatsii (uchebno-prakticheskii) k ch. 3 (Commentary on the Civil Code of the Russian Federation (educational and practical) to Part 3) / ed by S. A. Stepanov. Moscow: Prospekt; Ekaterinburg: Institut chastnogo prava, 2015. 152 p. (In Russian).

9. Matveev I. V. Nasledstvennyi dogovor: zarubezhnyi opyt i perspektivy poyavleniya v grazhdanskom prave Rossiisko Federatsii (Hereditary contract: foreign experience and prospects of emergence in the civil law of the Russian Federation) URL: http://отрасли-права.pф/article/9392 (Accessed: 21.05.2019). (In Russian).

10. Medvedev S. N. Vvedenie v grazhdanskoe pravo Ispanii. (Introduction to Spanish Civil Law). Stavropol': NCFU publ., 2017. 139 p. (In Russian).

11. Meier D. I. Russkoe grazhdanskoe pravo. (Russian civil law) Parrt 2. Moscow, 1997. 455 p. (In Russian).

12. Mel'nikova M. P. Nasledovanie po zakonu v Rossii ot Svoda zakonov do Grazhdanskogo kodeksa RSFSR 1964 goda (istoriko-teoreticheskii aspekt) (Inheritance by law in Russia from the Code of Laws to the Civil Code of the RSFSR of 1964 (historical and theoretical aspect): thesis. Stavropol', 2001. 222 p. (In Russian)

13. Mel'nikova M. P., Komarevtseva I. A. Rossiiskoe nasledstvennoe zakonodatel'stvo: analiz poslednikh izmenenii perspektivy razvitiya (Russian hereditary legislation: analysis of recent changes and development prospects) // Pravovaya politika i pravovaya zhizn'. 2017. No.1. P.109-117. (In Russian).

14. Mit'kevich A. O forme zaveshchanii. Istoriko-yuridicheskii ocherk. (On the form of wills. Historical and legal essay.) Tiflis, b/d. (In Russian).

15. Obzor del, rassmotrennykh Konstitutsionnym Sudom Rossiiskoi Federatsii (Review of cases considered by the Constitutional Court of the Russian Federation) // Sravnitel'noe konstitutsionnoe obozrenie. 2014. No.1. P. 149-157. (In Russian).

16. Pilipson E. G. Instituty dogovornogo nasledovaniya: pravovye problemy implementatsii na territorii rossiiskoi federatsii // Konsul'tantPlyus. (In Russian).

17. Pokrovskii I.A. Osnovnye problemy grazhdanskogo prava. (The main problems of civil law). Moscow: Statut, 1998. 353p (In Russian)

18. Sergeev A. P., Tolstoi Yu. K., Eliseev I. V. Kommentarii k grazhdanskomu kodeksu Rossiiskoi Federatsii (postateinyi). (Commentary on the Civil Code of the Russian Federation (itemized). Moscow: Prospekt, 2006. 304 p. (In Russian)

19. Serebrovskii V. I. Izbrannye trudy po nasledstvennomu i strakhovomu pravu. (Selected Works on Inheritance and Insurance Law). Moscow: Statut, 1997. 567 p. (In Russian).

20. Tarasova I. N. Ponyatie i znachenie formy zaveshchaniya $v$ rossiiskom grazhdanskom prave (The concept and meaning of the form of testament in Russian civil law) // Nasledstvennoe pravo. 2014. No.3. P.35 - 38. (In Russian)

21. Cheremnykh G. G.. Nasledstvennoe pravo Rossii: uchebnik. (Inheritance law of Russia: a textbook). Moscow: Eksmo 2009. 510 p. (In Russian).

\section{Информация об авторах}

Комаревцева Ирина Алексеевна - кандидат юридических наук, доцент кафедры гражданского права и процесса юридического института Северо-Кавказского федерального университета (Ставрополь) / Irak77@yandex.ru

Мельникова Марина Петровна - кандидат юридических наук, заведующая кафедрой гражданского права и процесса юридического института Северо-Кавказского федерального университета (Ставрополь) / mp.melnikova2012@ yandex.ru

\section{Information about the authors}

Komarevtseva Irina - PhD in Law, Associate Professor, Chair of Civil Law and Processes, Institute of Law, NorthCaucasus Federal University (Stavropol) / |rak77@ yandex.ru

MeInikova Marina - PhD in Law, Associate Professor, Chair of Civil Law and Processes, Institute of Law, North-Caucasus Federal University (Stavropol) / mp.melnikova2012@yandex.ru 